\title{
Analysis of a Notch Loaded Miniaturized Multifrequency Microstrip Patch Antenna
}

\author{
Sudipta Das ${ }^{1 *}$, Partha Pratim Sarkar ${ }^{2}$ and Santosh Kumar Chowdhury ${ }^{3}$ \\ ${ }^{1 *}$ Department of ECE, IMPS CET, Malda, W.B, INDIA \\ ${ }^{2}$ Department of Engineering and Technological Studies, University of Kalyani, \\ Nadia, W.B, INDIA \\ ${ }^{3}$ Ex-Professor, Department of Electronics and Tele-Communication Engineering, \\ Jadavpur University, Kolkata, W.B. INDIA \\ ${ }^{1 *}$ Sudipta.das1985@gmail.com, ${ }^{2}$ parthabe91@yahoo.com, \\ 3 santoshkumarchowdhury@gmail.com
}

\begin{abstract}
A miniaturized microstrip patch antenna with multifrequency operation is proposed in this paper. The effect of rectangular notch loading on microstrip patch is investigated in this paper. Two rectangular notches are introduced on the radiating patch and multifrequency response has been obtained. The first resonant frequency has been drastically reduced to $3.44 \mathrm{GHz}$ due to incorporation of rectangular notches. Compared to the conventional rectangular patch antenna, the proposed antenna can achieve reduction in patch size up to $64.3 \%$ with a frequency ratio of about 1.80 . The proposed antenna resonates at 3.44, 4.72, and $6.32 \mathrm{GHz}$ in microwave $S$ and $C$ band. The characteristic parameters of the proposed antenna are investigated by method of momentbased IE3D software. Theoretical results have been validated by measured results. Good agreement is observed between the theoretical and practical results. The proposed antenna could be promising for a number of applications such as Wi-Max, INSAT, and radar communications.
\end{abstract}

Keywords: Miniaturization, Multi-resonance effect, Rectangular Notch, Microstrip patch antenna

\section{Introduction}

The wireless communication systems have been developed widely and rapidly during the last decade. The size of wireless communication devices depends on the size of the components used inside these devices. In recent years, the demand for miniaturized antennas is also increased due to rapid decrease in size of wireless communication devices. Presently, certain specific bands of frequencies are allotted for different wireless communication systems. The required multiple frequency bands cannot be covered by a single conventional antenna. Again, the usage of many antennas is usually restricted by the volume and cost constraints of the applications. So a single antenna with multiple resonant frequencies may be the alternative choice. Thus, the design of light weight miniaturized multiband antenna has attracted much attention of the antenna community for applications in modern wireless communication systems. In recent days, microstrip patch antennas are highly utilized for applications in wireless communication due to its compact, planar, low cost, and light weight features. A number of design methods have been suggested by the researchers to increase the compactness of microstrip patch antenna [1-12]. Compact operation of air substrate patch antenna with more than 50\% size reduction was reported by Wong et al. [1]. Clasen et al. [2] proposed meshed antenna geometry and reported 30\% size reduction. Elsdon et al. [3] reported size reduction of up 
to $40 \%$ by using planar feeding. Size reduction of about $44 \%$ was reported by implementing a sector slot on circular patch antenna [4]. A compact E shaped patch antenna with corrugated wings was proposed which results in $25 \%$ size reduction [5]. A maximum size reduction of $41 \%$ was reported by varying the dimension of slots and feeding point on microstrip patch [6]. Zhao et al. [7] designed a compact patch antenna with $29.3 \%$ size reduction using split ring resonator embedded substrate. A square microstrip antenna designed with four slits and a pair of truncated corner results in $39 \%$ reduction in antenna size [8]. Hanae et al.[9] investigated the effect of defected ground structure (DGS) on microstrip patch antenna to provide a miniaturization of $50 \%$. An annular ring embedded L-slot rectangular microstrip patch antenna was implemented with $29.91 \%$ reduction resonance frequency [10]. A quasi fractal microstrip antenna using electromagnetic band gap structure was implemented which results in $35.6 \%$ size reduction [11]. Recently, Meng et al. [12] designed a 31\% miniaturized dual band modified patch antenna. Several investigations were also carried out by the researchers for the design of multifrequency microstrip antenna to support multiple communication systems [13-17]. Multifrequency operation can be obtained by using more than one element (multiple patches) with different sizes that resonates at different frequencies [13]. A slot loaded bowtie patch antenna is also a choice for achieving multifrequency operation [14]. Spiral shaped printed antenna is also investigated for achieving multifrequency operation [15]. Multifrequency operation can also be achieved using fractal microstrip patch antenna [16]. The multi-resonance effect from a microstrip patch can also be realized by using unequal resonance patch lengths [17]. The work presented in this paper relates to design of a compact multifrequency microstrip patch antenna. Our aim is to achieve multiple resonant frequencies and also compactness from a single microstrip patch antenna. Multiple resonant frequencies are obtained due to introduction of unequal rectangular notches on the microstrip patch, and also the size of the antenna has been reduced by $64.3 \%$ in comparison to conventional rectangular microstrip antenna with same patch area. The novelty of our work is size reduction and multifrequency operation from a single antenna with considerable peak gain of about 5.25dBi.

\section{Antenna Configuration}

\subsection{Antenna 1(Conventional Antenna)}

The configuration of the conventional rectangular reference antenna is given in Figure 1. The dielectric material selected for this design is an FR4 substrate with dielectric constant $\left(\varepsilon_{r}\right)=4.4$ and substrate height $(h)=1.5875 \mathrm{~mm}$. The length and width of Antenna 1 (conventional antenna) operating at $5.5 \mathrm{GHz}$ are 12 and $16 \mathrm{~mm}$, respectively [18]. The coaxial probe-feed of radius $0.5 \mathrm{~mm}$ with a simple ground plane arrangement is located at a position $W / 2(8 \mathrm{~mm})$ and $L / 3(4 \mathrm{~mm})$ from right side edge of the patch for best impedance matching.

\subsection{Antenna 2 (Proposed Antenna)}

The configuration of antenna 2 (proposed antenna) is shown in Figure 2. The proposed antenna is also designed with a similar FR-4 substrate. Two unequal rectangular notches are introduced at the left side and top edge of the patch to reduce the size of the antenna by reducing the resonant frequency and also to obtain multiple frequencies from the antenna. The addition of rectangular notches improves the gain and reflection coefficient of the proposed antenna at multiple resonant frequencies. The coaxial probe is fed at an optimized location $(X=2 \mathrm{~mm}, Y=-1 \mathrm{~mm})$ from patch centre $(X=0 \mathrm{~mm}, Y=0 \mathrm{~mm})$ for achieving multifrequency operation with best impedance matching. The method of moment based electromagnetic simulator IE3D [19] is applied for parametric investigation in the proposed antenna design. The optimal dimensions of the proposed 
antenna are given as: $L=12 \mathrm{~mm}, W=16 \mathrm{~mm}, W_{1}=4 \mathrm{~mm}, L_{1}=5 \mathrm{~mm}, L_{2}=2 \mathrm{~mm}, W_{2}=4$ $\mathrm{mm}$. The fabricated prototype of the proposed antenna is shown in Figure 3.

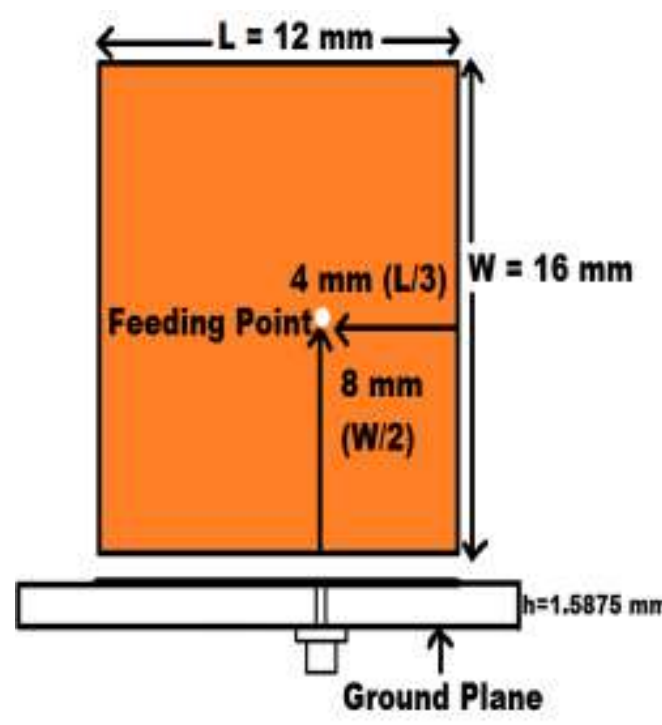

Figure 1. Configuration of Antenna 1 (Conventional Antenna)

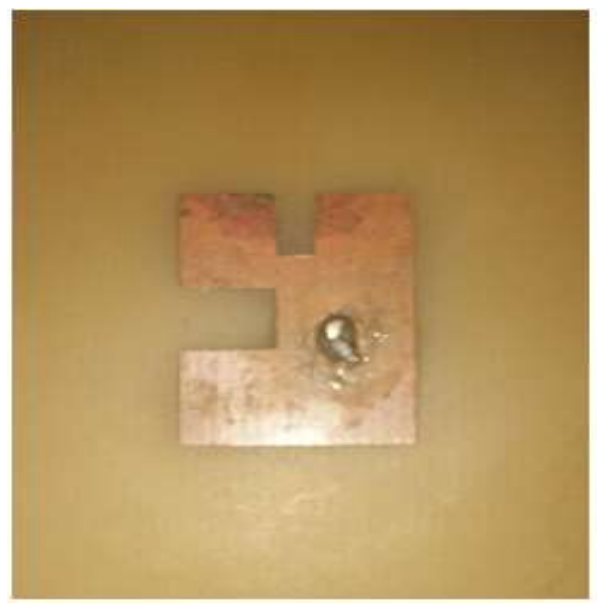

(a)

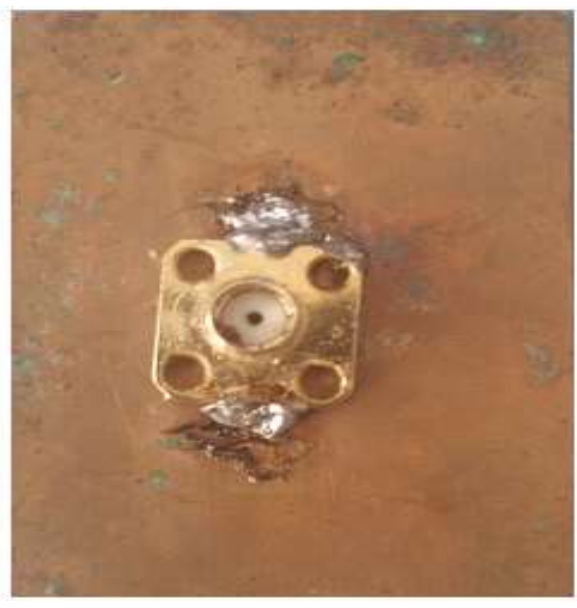

(b)

Figure 3. Fabricated Prototype of the Proposed Antenna (a) Patch, (b) Ground Plane

\section{Effect on Each Optimized Slot on the Performance of the Proposed Antenna}

The effect of each optimized notch on the resonant characteristics of the proposed antenna is analyzed using IE3D software. Figure 4 shows the different stages of modifications and corresponding simulated reflection coefficients. The Case I represent the conventional reference antenna (antenna without notch) which resonates at $5.5 \mathrm{GHz}$. But the resonance characteristics of the conventional rectangular antenna changes significantly due to the presence of unequal rectangular notches. In case II (presence of top notch), the antenna resonates at two different frequencies 4.72 and $6.66 \mathrm{GHz}$ with $\mathrm{S}_{11}$ below $-10 \mathrm{~dB}$. Another resonance is observed at $4.38 \mathrm{GHz}$ with $\mathrm{S}_{11}$ parameter $-6.27 \mathrm{~dB}$. At the final stage i.e., case III (proposed antenna), the first resonant frequency is achieved 
at $3.44 \mathrm{GHz}$ with improved reflection coefficient $\left(\mathrm{S}_{11}\right.$ parameter) of $-16 \mathrm{~dB}$, due to addition of second (left) rectangular notch. The second resonant frequency remains same (i.e., $4.72 \mathrm{GHz})$ with better reflection coefficient $(-17 \mathrm{~dB})$. The third resonant frequency is slightly shifted to $6.32 \mathrm{GHz}$ with reflection coefficient $-24 \mathrm{~dB}$.

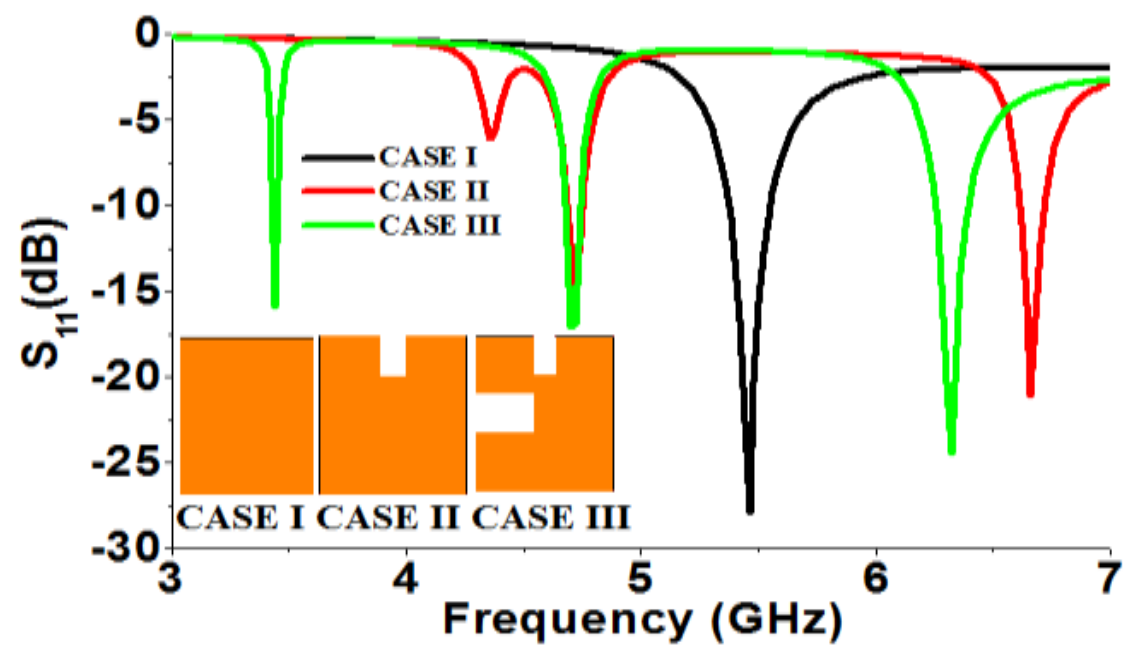

Figure 4. $S_{11}$ Variations of the Antenna in Different Cases

The variations of resonant frequency, reflection coefficient $\left(S_{11}\right.$ parameter), VSWR and gain in different cases of evolution of proposed antenna are summarized below in Table 1 .

\section{Table 1. Variations of Simulated Results in Different Cases of Evolution of Proposed Antenna}

\begin{tabular}{|c|c|c|c|c|}
\hline $\begin{array}{c}\text { Different } \\
\text { Cases }\end{array}$ & $\begin{array}{c}\text { Resonant } \\
\text { Frequency } \\
(\mathbf{G H z})\end{array}$ & $\begin{array}{c}\mathbf{S}_{\mathbf{1 1}} \\
\mathbf{( d B})\end{array}$ & $\begin{array}{c}\text { Gain } \\
\mathbf{( d B i})\end{array}$ & VSWR \\
\hline Case I & $f_{1}=5.5$ & -26.5 & 4.27 & 1.099 \\
\hline Case II & $f_{1}=4.36$ & -6.27 & 0.199 & 2.88 \\
& $f_{2}=4.72$ & -14.6 & 4.96 & 1.45 \\
& $f_{3}=6.66$ & -21 & 3.0 & 1.19 \\
\hline Case III & $f_{1}=3.44$ & -16 & 4.75 & 1.38 \\
(Proposed) & $f_{2}=4.72$ & -17 & 5.25 & 1.32 \\
& $f_{3}=6.32$ & -24 & 4.75 & 1.12 \\
& & & & \\
\hline
\end{tabular}

\section{Theoretical Considerations}

A simple rectangular microstrip patch antenna can be modeled as a parallel combination of RLC circuit. The current flows from the feeding point to the top and bottom edges of the patch. The equivalent circuit a conventional rectangular microstrip patch antenna is shown in Figure 5, where $\mathrm{R}_{1}, \mathrm{~L}_{1}$ and $\mathrm{C}_{1}$ can be defined as [20]

$C_{1}=\frac{\varepsilon_{e} \varepsilon_{0} L W}{2 h} \cos ^{-2}\left(\pi x_{0} / L\right)$

$L_{1}=\frac{1}{\omega^{2} C_{1}}$

$R_{1}=\frac{Q_{r}}{\omega C_{1}}$

Where, $\mathrm{L}=$ Length of the rectangular patch, $\mathrm{W}=$ Width of the rectangular patch, $x_{0}=$ feed point location along the length of the patch, $h=$ thickness of the substrate material 
and $\mathrm{Q}=\frac{C \sqrt{\varepsilon_{e}}}{4 f h}$, where $\mathrm{c}=$ velocity of light, $\mathrm{f}=$ design frequency and $\varepsilon_{e}=$ effective permittivity of the medium which is given by [20] as:

$\varepsilon_{e}=\frac{\varepsilon_{r}+1}{2}+\frac{\varepsilon_{r}-1}{2}\left[1+10 \frac{h}{w}\right]^{-1 / 2}$ (4) Where, $\varepsilon_{r}=$ relative permittivity of the substrate.

The rectangular notches agitate the surface current path, initiating an inductive and capacitive effect that is responsible for multi-resonance characteristics of the proposed antenna. Due to the effect of the notches, two types of current paths, one is the normal patch current and resonates at the design frequency of the initial patch; however, the other current flows around the notches consequently alter the resonance frequency. With the introduction of notches, the resonance behavior of the antenna changes because each notch introduces additional series inductance $\left(\Delta \mathrm{L}_{1}, \Delta \mathrm{L}_{2}\right)$ and series capacitance $\left(\Delta \mathrm{C}_{1}\right.$, $\Delta \mathrm{C}_{2}$ ) that modify the equivalent circuit of the rectangular microstrip patch antenna as shown in Figure 6, in which the additional series inductances and series capacitances can be calculated as [21].

$$
\begin{aligned}
\Delta \mathrm{L}_{1} & =\frac{h \mu_{0} \pi}{8}\left(\frac{L_{n 1}}{L}\right)^{2} \\
\Delta \mathrm{C}_{1} & =\left(\frac{L_{n 1}}{L}\right) \cdot C_{S} \\
\Delta \mathrm{L}_{2} & =\frac{h \mu_{0} \pi}{8}\left(\frac{L_{n 2}}{L}\right)^{2} \\
\Delta \mathrm{C}_{2} & =\left(\frac{L_{n 2}}{L}\right) \cdot C_{S}
\end{aligned}
$$

Where, $\mu_{0}=4 \pi \times 10^{-7} \mathrm{H} / \mathrm{m}, L_{n 1}=$ depth of the horizontal slot, $L_{n 2}=$ depth of the vertical slot, $\mathrm{C}_{\mathrm{s}}=$ gap capacitance given by [22]. The simplified circuit model of proposed antenna is shown in Figure 7, where, $C_{2}=\frac{C_{1} \cdot\left(\Delta C_{1}+\Delta C_{2}\right)}{\left(C_{1}+\Delta C_{1}+\Delta C_{2}\right)}, L_{2}=L_{1}+\Delta L_{1}+\Delta L_{2}$. Due to multi path of current flowing there exist multi resonant frequency.

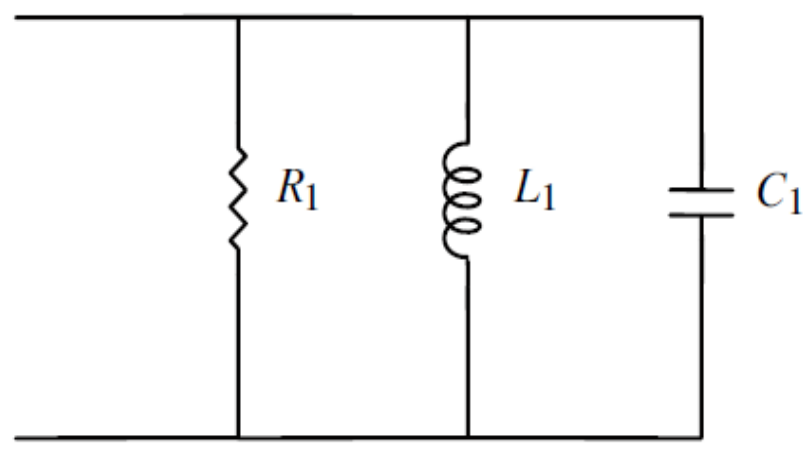

Figure 5. Equivalent Circuit of the Conventional Rectangular Patch Antenna for Normal Current Path

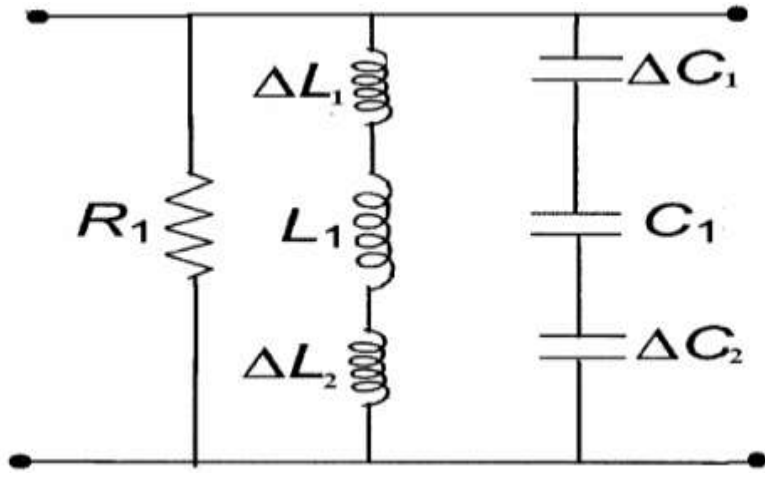

Figure 6. Equivalent Circuit of the Proposed Antenna due to the effect of notches 


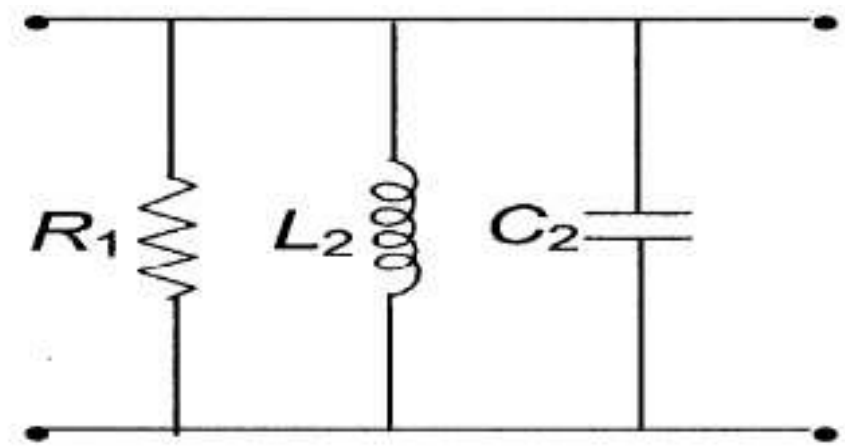

Figure 7. Equivalent Circuit of the Proposed Antenna due to Current Path around the Notches

\section{Parametric Study and Analysis of the Proposed Antenna}

The parametric study of the proposed antenna has been carried out using MOM based IE3D software to study the effects of various parameters on the performance of the antenna. The effects of the parameters are analyzed by slightly changing only one structural parameter from the reference design at the time of simulation while all other parameters remain fixed.

\subsection{Effect of Antenna Parameter $W_{1}$}

The impact of design parameter $\mathrm{W}_{1}$ is shown in Figure 8. It is clearly seen that the first resonant frequency can be varied by changing the value of $\mathrm{W}_{1}$ parameter. An optimum value of $\mathrm{W}_{1}=4 \mathrm{~mm}$ is selected as a notch parameter for the design of the antenna. Further increase of $\mathrm{W}_{1}$ than proposed dimension will slightly shift the first resonant frequency to a lower value but the reflection coefficient ( $S_{11}$ parameter) is not under -10 $\mathrm{dB}$ level, which indicates poor impedance matching. The second and third frequency band remains almost unchanged with the variation of $\mathrm{W}_{1}$ parameter.

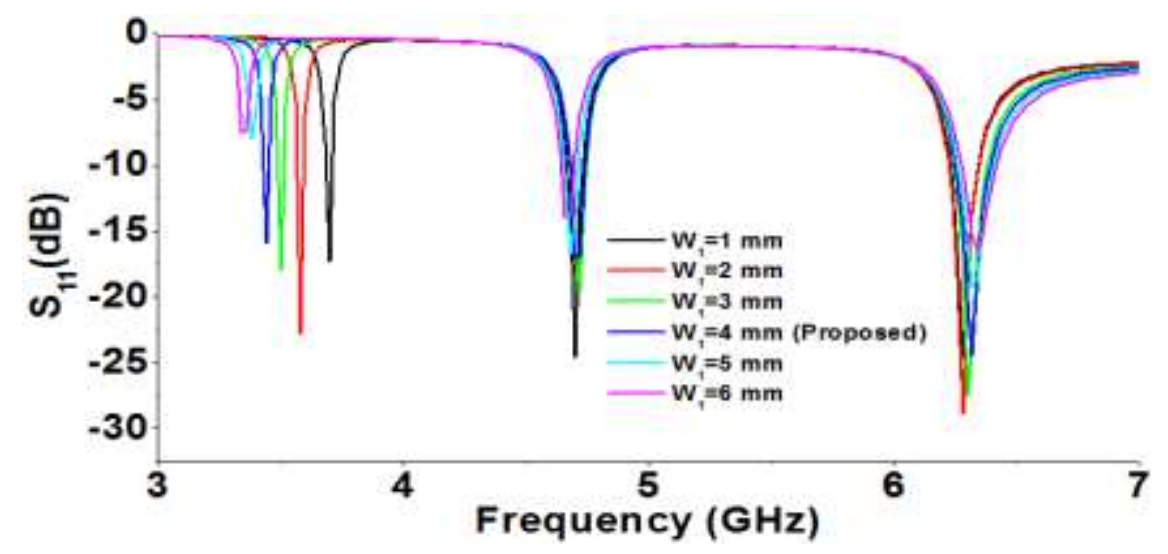

Figure 8. $S_{11}$ Variations for Different Values of $W_{1}$

\subsection{Effect of Antenna Parameter $L_{1}$}

The effect of design parameter $\mathrm{L}_{1}$ on the resonant characteristics of the proposed antenna is shown in Figure 9. Maximum shifting of the first resonant frequency with good impedance matching is obtained for the proposed dimension. So, an optimum value of $L_{1}$ $=5 \mathrm{~mm}$ is selected as a notch parameter for which maximum size reduction is obtained. When $\mathrm{L}_{1}$ is increased to $6 \mathrm{~mm}$, the first resonant frequency is decreased to $3.14 \mathrm{GHz}$ with $\mathrm{S}_{11}$ of only $-7 \mathrm{~dB}$, which suggests poor impedance matching. The excitation of first resonant frequency is not possible with further increase in $L_{1}$ parameter of the proposed 
antenna. It is observed that the shifting of second and third resonant frequency depends inversely on the dimension of $\mathrm{L}_{1}$ parameter of the antenna.

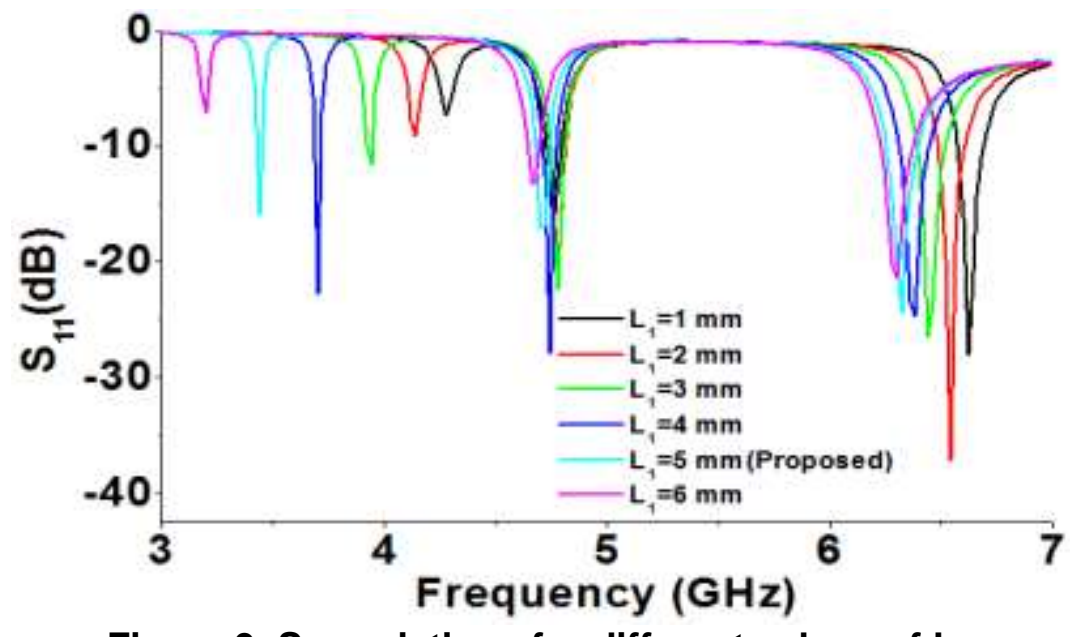

Figure 9. $S_{11}$ variations for different values of $L_{1}$

\subsection{Effect of Antenna Parameter $W_{2}$}

Figure 10 illustrate the variations of $S_{11}$ parameter versus frequency due to change in notch parameter $\mathrm{W}_{2}$. The first resonant frequency can be shifted to a lowest value of 3.34 $\mathrm{GHz}$ but the value of reflection coefficient $\left(\mathrm{S}_{11}\right.$ parameter) at $3.34 \mathrm{GHz}$ decreases to $-7.29 \mathrm{~dB}$ due to impedance mismatching. The value of $S_{11}$ should be at least $-10 \mathrm{~dB}$ for an antenna to radiate in the far field region. So, an optimum value of $4 \mathrm{~mm}$ is selected for $\mathrm{W}_{2}$ to achieve an optimal design of the proposed antenna. The notch parameter ' $\mathrm{W}_{2}$ ' has a great impact on resonant frequency of the second mode. The second resonant frequency can be tuned from 5.45 to $4.35 \mathrm{GHz}$ by increasing the values of $\mathrm{W}_{2}$ parameter from 1 to 5 $\mathrm{mm}$. The third resonant frequency can also be easily adjusted by changing the values of the design parameter $\mathrm{W}_{2}$.

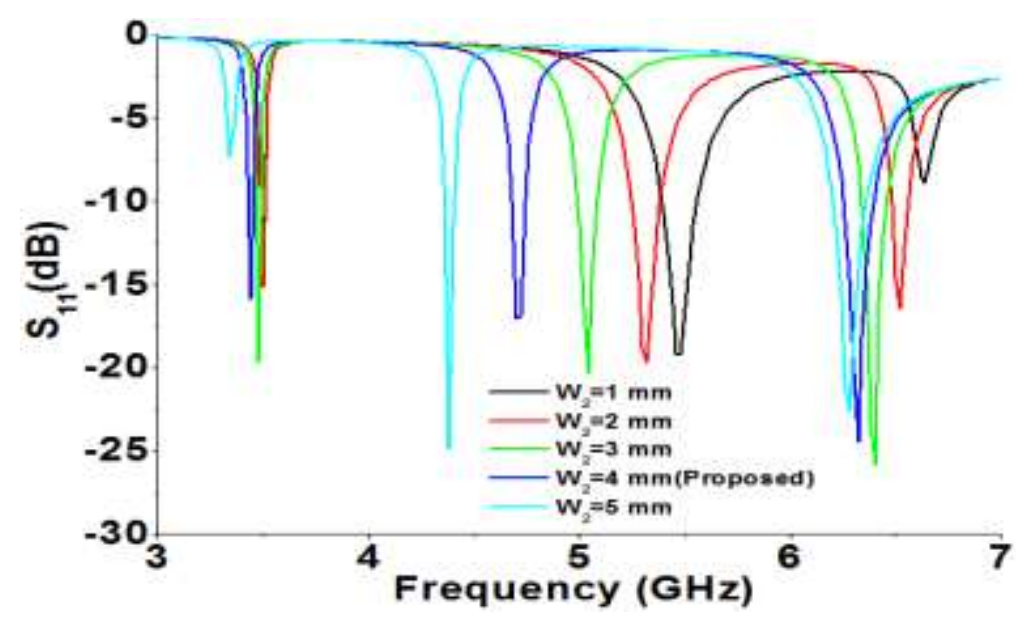

Figure 10. $S_{11}$ Variations for Different Values of $W_{2}$

\subsection{Effect of Antenna Parameter $\mathrm{L}_{2}$}

The variations of $S_{11}$ curves for different values of antenna parameter $L_{2}$ are illustrated in Figure 11. The resonant frequency of the second mode can be easily tuned from 4.86 to $4.58 \mathrm{GHz}$ by changing the dimension of parameter $\mathrm{L}_{2}$ from 1 to $4 \mathrm{~mm}$. The first and third resonant frequency remains unchanged due to variations in $\mathrm{L}_{2}$ parameter. But maximum 
reflection coefficient for the first resonant frequency is observed at $\mathrm{L}_{2}=2 \mathrm{~mm}$. So, $\mathrm{L}_{2}=2$ $\mathrm{mm}$ is selected as an optimum value for the design of the antenna.

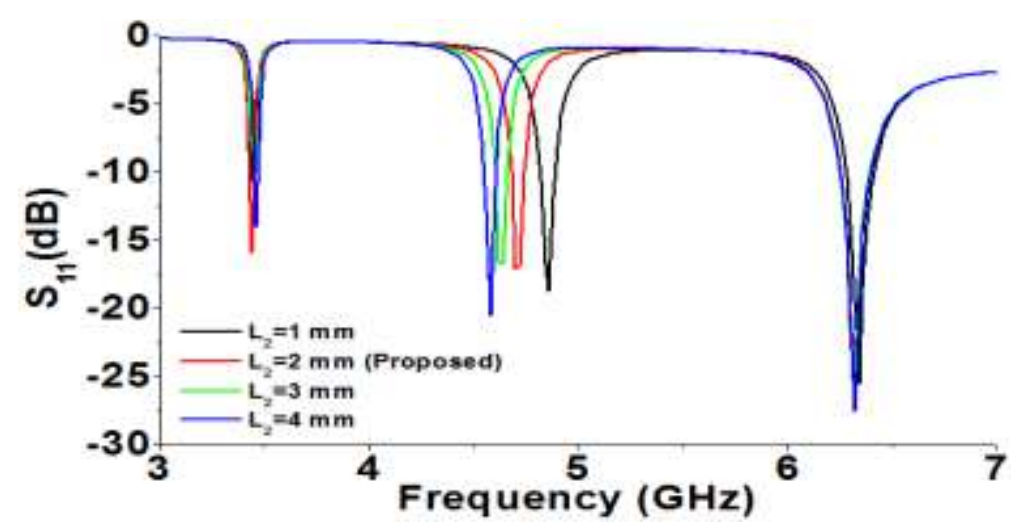

Figure 11. $S_{11}$ Variations for Different Values of $L_{2}$

The function of the geometrical mechanism of the proposed antenna at three resonant modes can also be explained with the help of the surface current distributions for different resonant frequencies. The surface current distribution of the conventional is shown in Figure 12(a). The surface current distributions of the conventional antenna changes due to presence of notches on the radiating patch. The surface current distributions in the notch loaded antenna (proposed antenna) are studied and displayed in Figures 12(a) - 12(d). It is clearly seen from Figure 12(b) that for $3.44 \mathrm{GHz}$ operation, the surface current is largely concentrated around the left rectangular notch $\left(\mathrm{W}_{1}, \mathrm{~L}_{1}\right)$ for which it is generated. For the $4.72 \mathrm{GHz}$ excitation [see Figure 12(c)], large surface current distribution is observed around the top rectangular notch $\left(\mathrm{W}_{2}, \mathrm{~L}_{2}\right)$ for which it is mainly generated and controlled. Finally, it is verified from Figure 12(d) that for third resonant mode at $6.32 \mathrm{GHz}$, surface current is much strongly distributed around both of the rectangular notches $\left(\mathrm{W}_{1}, \mathrm{~L}_{1}\right.$, and $\mathrm{W}_{2}, \mathrm{~L}_{2}$ ) of the proposed antenna. So, the excitation of third resonant mode is influenced by the dimensions of both of the notches. Thus, both from the $S_{11}$ characteristic curves and surface current distributions, we can clearly comprehend the function of the related geometrical mechanism of the proposed antenna at three resonant modes. The current mainly concentrates at the edges of the notches. The current path increases due to lengthening of the surface current around the notches which leads to the miniaturization of the proposed antenna by decreasing the resonant frequency. The number of resonant frequency increases due to the disturbance caused to the mean current paths of any resonant mode. 


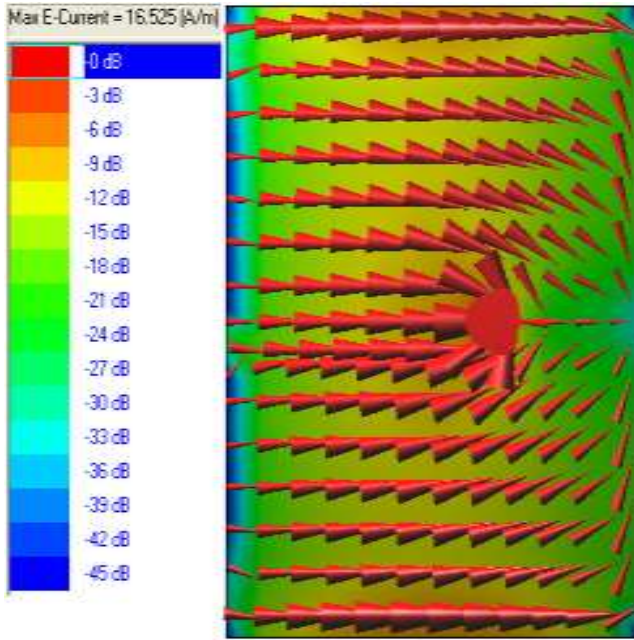

(a)
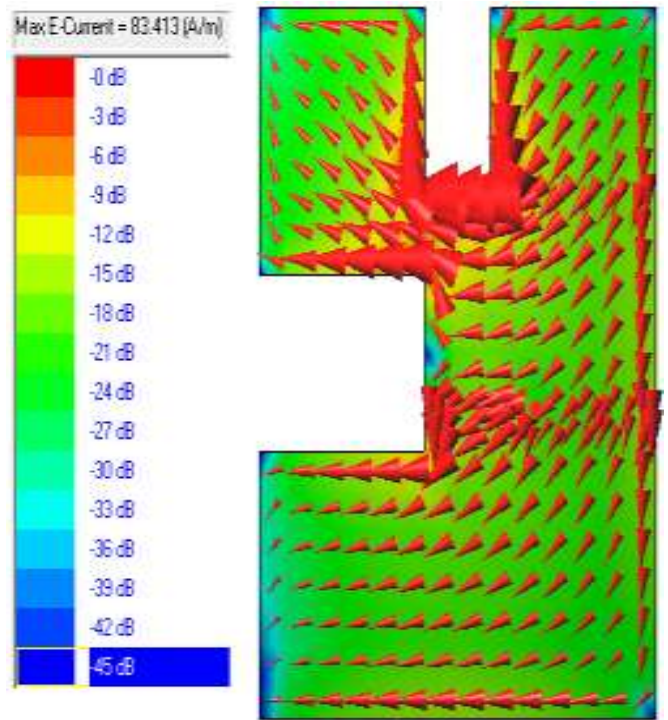

(c)
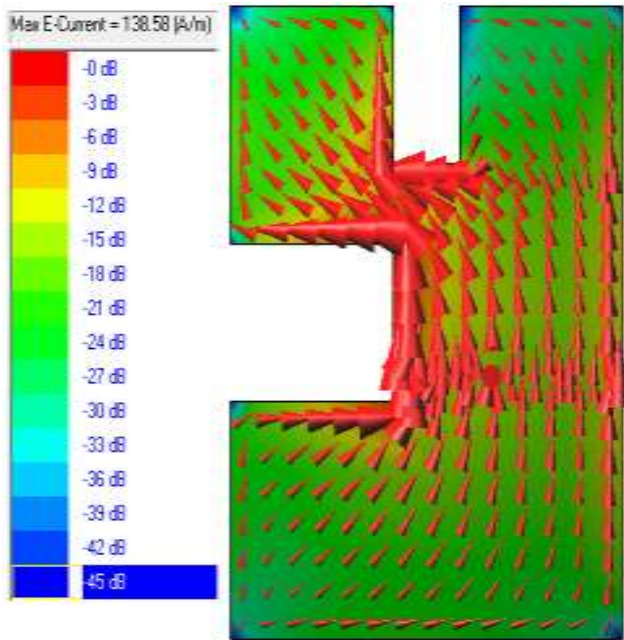

(b)
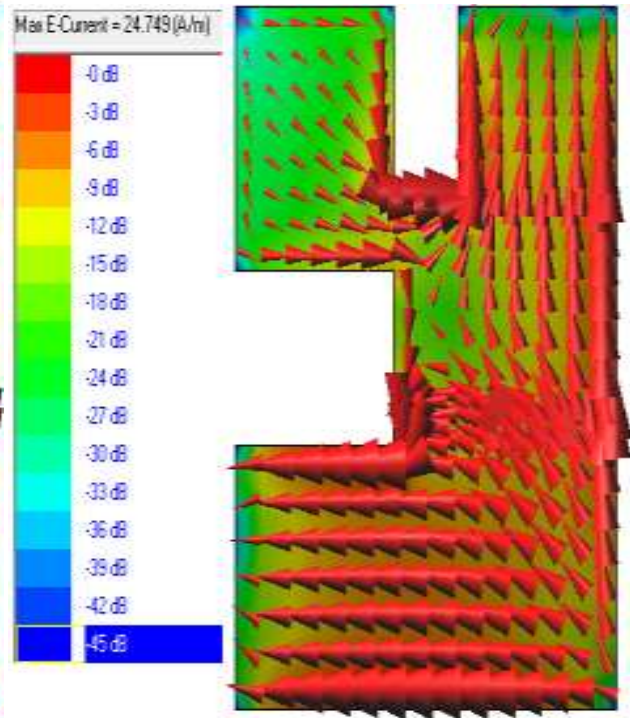

(d)

Figure 12. Surface Current Distribution of Antenna1 (Conventional) at (a) 5.5 GHz and Antenna 2 (Proposed) at (b) $3.44 \mathrm{GHz}$ (c) $4.72 \mathrm{GHz}$ (d) $6.32 \mathrm{GHz}$

\section{Results and Discussion}

The reflection coefficient of the proposed antenna was measured using Agilent E5071B vector network analyzer. The comparison of the measured and simulated reflection coefficient $\left(S_{11}\right.$ parameter) of the proposed antenna is shown in Figure 13. A significant improvement of frequency reduction is achieved in proposed microstrip antenna with respect to the conventional antenna structure. Due to the presence of notches in the antenna, the simulated results show that the first resonant frequency is reduced to $3.44 \mathrm{GHz}$ with $\mathrm{S}_{11}$ of about $-16 \mathrm{~dB}$, the second resonant frequency is obtained at 4.72 $\mathrm{GHz}$ with $\mathrm{S}_{11}-17 \mathrm{~dB}$, and third resonant frequency is obtained at $6.32 \mathrm{GHz}$ with $\mathrm{S}_{11}$ of about $-24 \mathrm{~dB}$, respectively. The measured result shows that the first resonant frequency is achieved at $3.42 \mathrm{GHz}$ with $\mathrm{S}_{11}$ of about $-14 \mathrm{~dB}$. The second and third resonant frequencies were measured at 4.76 and $6.16 \mathrm{GHz}$ with $S_{11}$ of about -16 , and $-20 \mathrm{~dB}$, respectively. The small discrepancy between the measured and simulated result is due to the effect of improper soldering of SMA connector or fabrication tolerance. The simulated VSWR of the proposed antenna is shown in Figure 14. The VSWR of the proposed 
antenna is within 1.4:1 which signifies much less reflected power due to better impedance matching and practically considerable mismatch loss throughout different resonant frequencies. The simulated gain and directivity of the proposed antenna is depicted in Figure 15. The simulated peak gain of about $5.25 \mathrm{dBi}$ is achieved at $4.72 \mathrm{GHz}$. The directivity of the proposed antenna lies above $6.0 \mathrm{dBi}$ for all of the operating frequencies. The total and radiation efficiency of the proposed antenna is shown in Figure 16. It is found that for lower frequency of operation, the radiation efficiency of the antenna is about $75 \%$. Peak radiation efficiency of about $77 \%$ is achieved at $4.72 \mathrm{GHz}$. The radiation patterns of the proposed antenna are shown in Figure 17 (a) - (b). The proposed antenna offers stable unidirectional radiation patterns in both $\mathrm{E}$ and $\mathrm{H}$ plane at respective frequencies with acceptable cross polarization level. The maximum radiation is exactly concentrated along $0^{\circ}$. The proposed antenna shows linear polarization in the broadside direction. The measured result of the proposed antenna is shown in Table 2.

\subsection{Process of Size Reduction Calculation}

\subsubsection{Antenna 1 (Conventional Reference Antenna)}

Resonant Frequency $\left(\mathrm{f}_{\mathrm{r}}\right)=5.45 \mathrm{GHz}$, The dimension of the patch $=16(\mathrm{~W}) \times 12(\mathrm{~L})$ $\mathrm{mm}^{2}$. The area of the conventional reference patch $=192 \mathrm{~mm}^{2}$.

\subsubsection{Antenna 2 (Notch Loaded Patch without Modified Ground Plane)}

Resonant frequency $\left(f_{r}\right)=3.44 \mathrm{GHz}$, The dimension of the patch $=20.3(\mathrm{~W}) \times 26.5$ (L) $\mathrm{mm}^{2}$, The new area of the patch $=537.95$

$\begin{aligned} \text { Size reduction } & =\frac{\text { New area of the patch }- \text { area of the conventional reference patch }}{\text { New area of the patch }} \times 100 \% \\ & =\frac{(537.95-192)}{537.5} \times 100 \%=64.30 \%\end{aligned}$

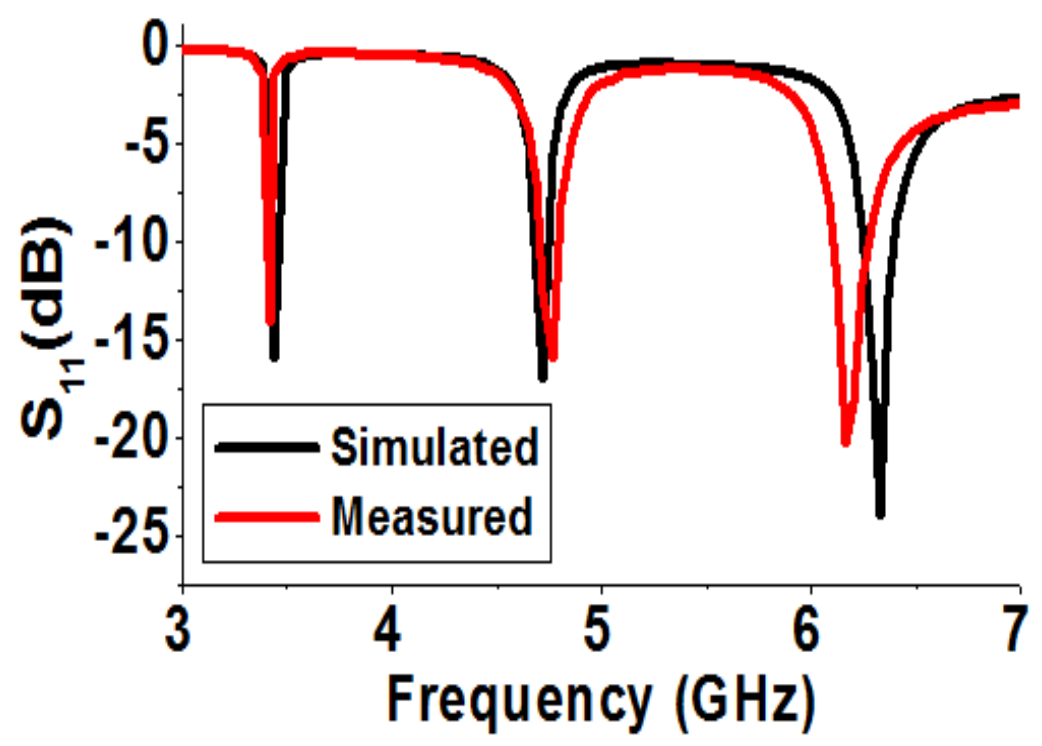

Figure 13. Reflection Coefficient $\left(S_{11}\right.$ parameter) of the Proposed Antenna 


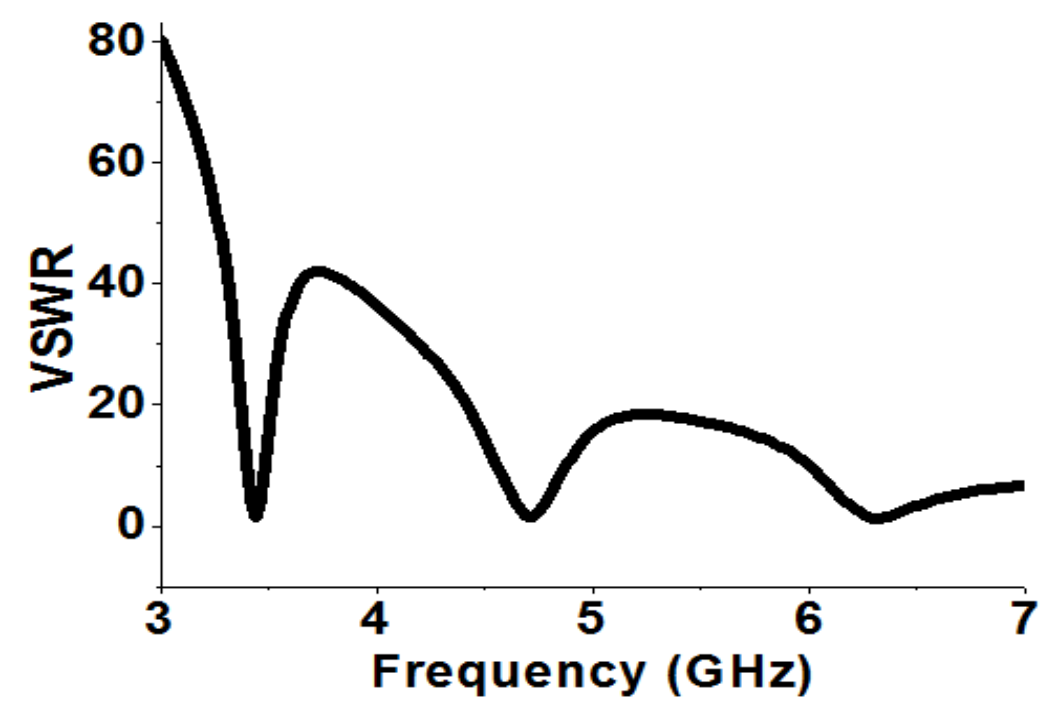

Figure 14. VSWR of the Proposed Antenna

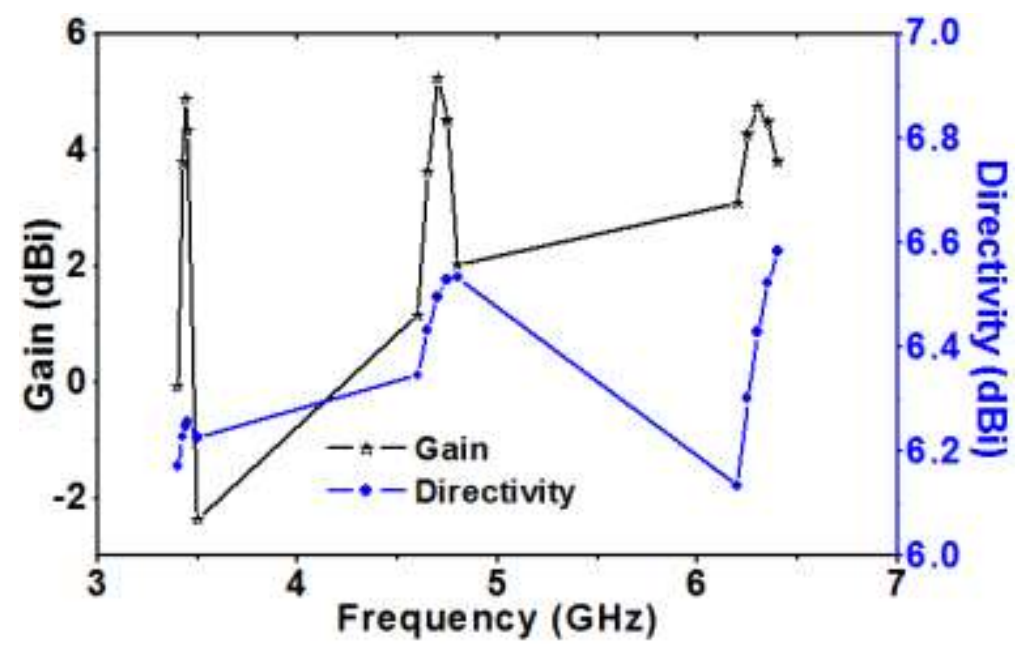

Figure 15. Gain and Directivity of the Proposed Antenna

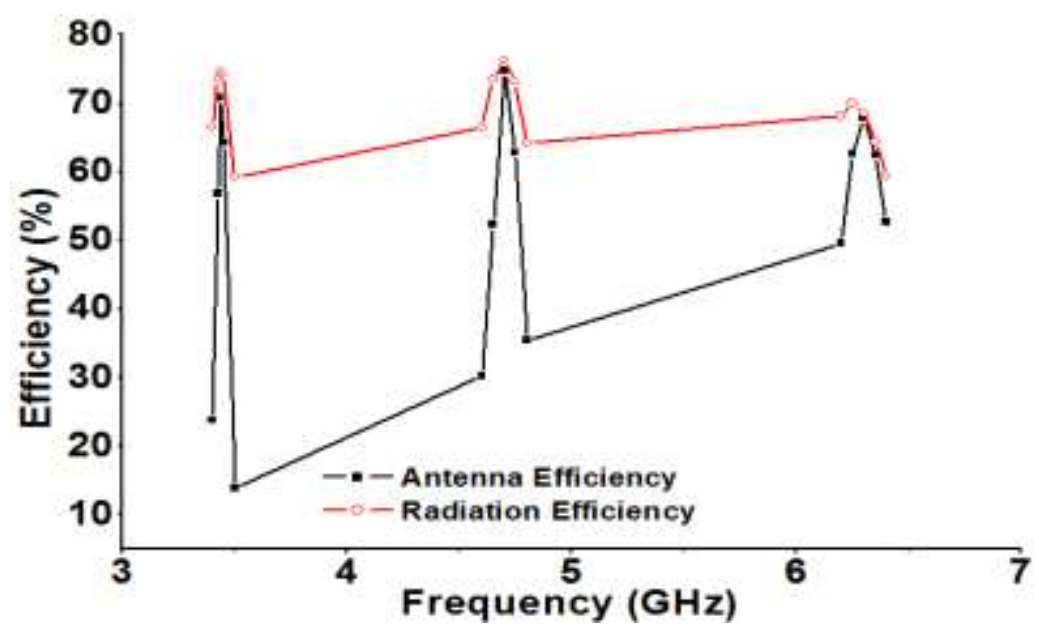

Figure 16. Plot of Efficiency versus Frequency of the Proposed Antenna 


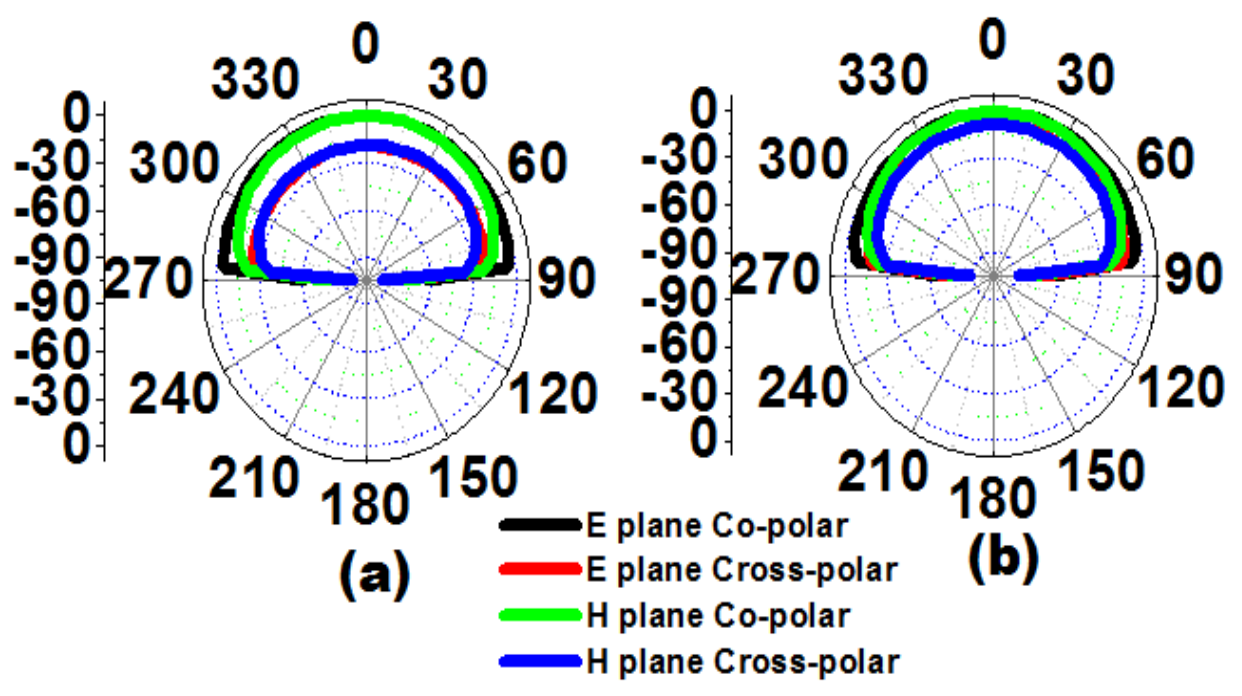

Figure 17. Radiation Pattern at (a) $3.44 \mathrm{GHz}$, (b) $4.72 \mathrm{GHz}$

Table 2. Measured Results of the Proposed Antenna

\begin{tabular}{|c|c|c|c|c|c|}
\hline Antenna & $\begin{array}{c}\text { Resonant } \\
\text { freq. } \\
\text { (GHz) }\end{array}$ & $\mathbf{S}_{\mathbf{1 1}}$ & $\begin{array}{c}-\mathbf{1 0 d B} \\
\text { Band } \\
\text { width } \\
\text { (MHz) }\end{array}$ & $\begin{array}{c}\text { Gain } \\
(\mathbf{d B i})\end{array}$ & $\begin{array}{c}\text { Frequency } \\
\text { Ratio }\end{array}$ \\
\hline Proposed & $\mathrm{f}_{1}=3.42$ & -14 & 40 & 5.0 & $\mathrm{f}_{2} / \mathrm{f}_{1}=1.391$ \\
Antenna & $\mathrm{f}_{2}=4.76$ & -16 & 100 & 4.9 & $\mathrm{f}_{3} / \mathrm{f}_{1}=1.801$ \\
& $\mathrm{f}_{3}=6.16$ & -20 & 180 & 5.5 & \\
\hline
\end{tabular}

\section{Conclusion}

This paper describes analysis and implementation of a rectangular notch loaded multifrequency printed antenna. The proposed antenna radiates three distinct frequencies i.e. $3.44,4.72$, and $6.32 \mathrm{GHz}$ with increased frequency ratio. The designed multifrequency antenna also offers $64.3 \%$ size reduction compared to the conventional reference antenna. An optimization between miniaturization and impedance matching is maintained in this work. Furthermore, good stable broadside radiation pattern and acceptable gain are also obtained across the operating frequencies. The proposed antenna is suitable for a number of modern wireless communication systems such as Wi-MAX (3.3-3.6 GHz), INSAT system (4.5-4.8 GHz), and microwave $\mathrm{S} \& \mathrm{C}$ band applications.

\section{References}

[1] K-L.Wong, and H-C.Tung, "An inverted U-shaped patch antenna for compact operation”, IEEE Trans on Antennas and Propag., Vol. 51, (2003), pp.1647 - 1648.

[2] G. Clasen, and R. Langley, "Meshed patch antennas", IEEE Transactions on Antennas and Propagation, Vol. 52, (2004), pp.1412-1416.

[3] M. Elsdon, A. Sambell, and Y. Qin, "Reduced size direct planar-fed patch antenna", Electronics Letters, Vol. 41, (2005), pp. 884-886.

[4] D. D. Krishna, C. K. Aanandan, P. Mohanan, and K. Vasudevan, "Circular microstrip antenna with a sector-slot for dual-port operation”, Microw. Opt. Technol. Lett., Vol. 48, (2006), pp.505-508.

[5] G.Yuehe, K. P. Esselle, and T. S. Bird, "A Compact E-Shaped Patch Antenna with Corrugated Wings", IEEE Trans. Antennas Propag. Vol. 54, (2006), pp 2411-2413.

[6] S. Bhunia, M. K. Pain, S. Biswas, D. Sarkar, P. P. Sarkar, and B. Gupta, "Investigations on microstrip patch antennas with different slots and feeding points," Microwave Opt. Technol. Lett., Vol. 50, (2008), pp.2754-2758.

[7] X. Zhao, Y. Lee, and J. Choi, "Design of a compact patch antenna using split-ring resonator embedded substrate”, Microw. Opt. Technol. Lett., Vol. 53, (2011), pp. 2786-2790. 
[8] A. K. Gautam, P. Benjwal, and B. K. Kanaujia, "A compact square microstrip antenna for circular polarization”, Microw. Opt. Technol. Lett., Vol. 54, (2012), pp.897-900.

[9] E. Hanae, N. A. Touhami, M. Aghoutane, S. El Amrani, A. Tazon, and M. Boussouis, "Miniaturized microstrip patch antenna with defected ground structure", Progress In Electromagnetics Research C, Vol. 55, (2014), pp.25-33.

[10] S. Dwivedi, S. G. Yadav, and A. K. Singh, "Annular ring embedded L-slot rectangular microstrip patch antenna”, IEEE Students' Technology Symposium, (2014), pp. $372-375$.

[11] E. E. C. D. Oliveira, A.G.D Assuncao, J. B. L.Oliveira, and A. M. Cabral, "Small size quasi fractal microstrip antenna M1 EBG-GP", International Journal of Applied Electromagnetics and Mechanics, Vol. 39, (2012), pp. 645-649.

[12] F. Meng, and S. Sharma, "A single feed dual band $(2.4 \mathrm{GHz} / 5 \mathrm{GHz})$ miniaturized patch antenna for wireless local area network (WLAN) communications," J Electromagn Waves Appl, Vol. 30, (2016), pp.2390-2401.

[13] A. Manassas, T. Kaifas, and K. Siakavara, "Multiband printed antenna for low frequencies WLAN applications", International Journal of Microwave and Optical Technology, Vol. 2, (2007), pp. 182-186.

[14] Y. Tawk, K.Y. Kabalan, A. El-Hajj, C.G. Christodoulou, and J. Constantine, "A simple multiband printed bowtie antenna”, IEEE Antennas and Wireless Propagation Letters, Vol. 7, (2008), pp. 557-560.

[15] J. H.Yoon, "Fabrication and measurement of modified spiral-patch antenna for use as a triple-band antenna”, Microwave Opt. Technol. Lett., Vol. 48, (2006), pp.1275-1279.

[16] S. Jagadeesha, R. M. Vani, and P. V. Hunagund, "Plus Shape Slotted Fractal Antenna for Wireless Applications", Wireless Engineering and Technology, Vol.3, (2012), pp.175-180.

[17] H. Malekpoor, and S. Jam, "Design of a multiband asymmetric patch antenna for wireless applications", Microwave Opt. Technol. Lett., Vol. 55, (2013), pp.730-734.

[18] C. A. Balanis, "Antenna theory analysis and design", Third Edition, pp.817-820, Wiley \& Sons.

[19] Zeland Software Inc., IE3D: MoM-based EM Simulator, Zeland Software Inc., Fremont, CA.

[20] R. Garg., P. Bhartia, I. Bahl, and A. Ittipiboon, "Microstrip Antenna Design Handbook", Artech House, Norwood, 2001.

[21] I. J. Bahal, "Lumped Elements for RF and Microwave Circuits", Artech House, Boston, 2003.

[22] M. K. Meshram, and B. R. Vishvakarma, "Gap-coupled microstrip array antenna for wide band operation”, Int. J. Electronics, Vol. 88, (2001), pp.1161-1175.

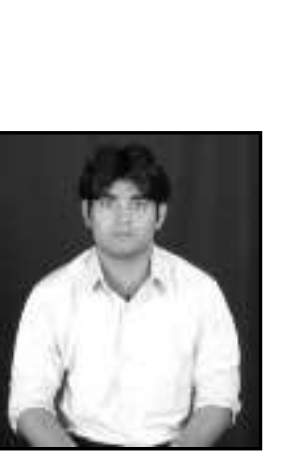

\begin{abstract}
Authors
Sudipta Das, is working as an Assistant Profeesor in Department of Electronics and Communication Engineering. He is presently pursuing Ph.D from University of Kalyani, INDIA. His area of research interests are Microstrip Antenna and Filter design. He has contributed almost 30 international research articles in various journals. The Biography of Mr. Sudipta Das is shortlisted for inclusion in the Thirty-Eighth $\left(38^{\text {th }}\right)$ Edition of the Dictionary of International Biography published by the "International Biographical Centre" of Cambridge, England. The Biography of Mr. Sudipta Das is selected in Marquis Who's who in the World 2016 ( $33^{\text {rd }}$ Edition).
\end{abstract}

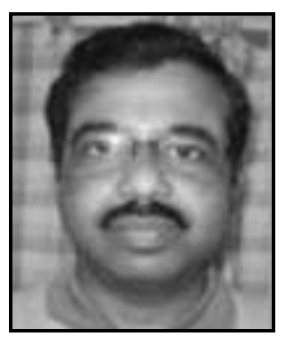

Partha Pratim Sarkar obtained his Ph.D in engineering from Jadavpur University in the year 2002. He is presently working as Senior Scientific Officer (Professor Rank) at the Dept. of Engineering \& Technological Studies, University of Kalyani. His area of research includes, Microstrip Antenna, Microstrip Filter, Frequency Selective Surfaces, and Artificial Neural Network. He has contributed more than 250 research articles in various journals and conferences of repute. He is also a life Fellow of IETE. 


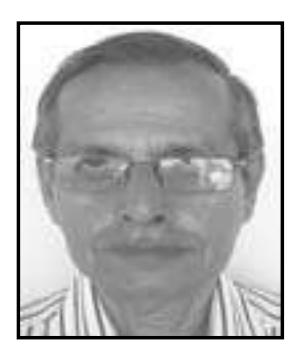

Santosh kr. Chowdhury, obtained his Ph.D in engineering from Jadavpur University in the year 1971. He is a Life senior member of IEEE, Life fellow of IETE, Fellow of IE, Fellow of West Bengal Academy of Science and Technology. His area of research includes Microstrip Antenna, Microstrip Filter, and Frequency Selective surfaces. He has contributed more than 400 international research articles in various journals and conferences of repute. 